\title{
RECENT ACTIVITIES IN MAGNETIC SEPARATION IN SWEDEN
}

\author{
YANMIN WANG AND ERIC FORSSBERG \\ Division of Mineral Processing, Luleå University of Technology, \\ S-971 87, Luleå, Sweden
}

\begin{abstract}
This paper describes some industrial applications of magnetic separation in Swedish mineral industry. Recent studies on magnetic treatment of minerals in Sweden are also presented. These studies involve selectivity of wet magnetic separation, wet magnetic recovery of mineral fines and ultrafines, sulphide processing by magnetic means, as well as dry magnetic purification of industrial minerals.
\end{abstract}

(Received April 19, 1995, accepted May 31, 1995)

\section{INTRODUCTION}

Magnetic separation, although used for many years in recovering iron minerals with high magnetic susceptibility, is still in infancy in Sweden when it comes to less obvious raw materials, such as industrial and sulphide minerals. On the other hand, problems associated with very fine particles when treated by magnetic means have not been completely solved. Therefore, some research projects on development and application of magnetic separation in mineral processing have proposed and carried out within the Swedish Mineral Processing Research Foundation (MinFo) during the recent years.

The projects covered magnetic recovery of very fine particles, sulphide mineral processing by magnetic separation, as well as dry purification of industrial minerals by the existing magnetic separators. At the same time, magnetic separation techniques have been successfully applied to the flowsheets for treatment of industrial minerals. 


\section{INDUSTRIAL APPLICATIONS OF MAGNETIC SEPARATION}

Sulphide Ore Processing by Wet Carousel HGMS

Boliden Mineral AB is the leading producer of concentrates of sulphide minerals in Sweden. Metals produced include $\mathrm{Zn}, \mathrm{Cu}, \mathrm{Pb}, \mathrm{Ag}$ and $\mathrm{Au}$. The sulphide minerals are recovered mainly by flotation. However, the flotation concentrates always contain traces of other metal sulphides. The lead concentrate, for instance, contains some $\mathrm{Cu}$ and $\mathrm{Zn}$. To recover zinc lost to the lead concentrate, a high-gradient magnetic separator was installed as a cleaner in the industrial flowsheet [1], as shown in Figure 1.

The separator used is the carousel Sala-HGMS model MK III with one head. The separator was manufactured by Sala International AB, Sweden. The maximum magnetic induction is 1.8 Tesla. The matrix is the standard expanded metal with approximately $3 \mathrm{~mm}$ mesh size.

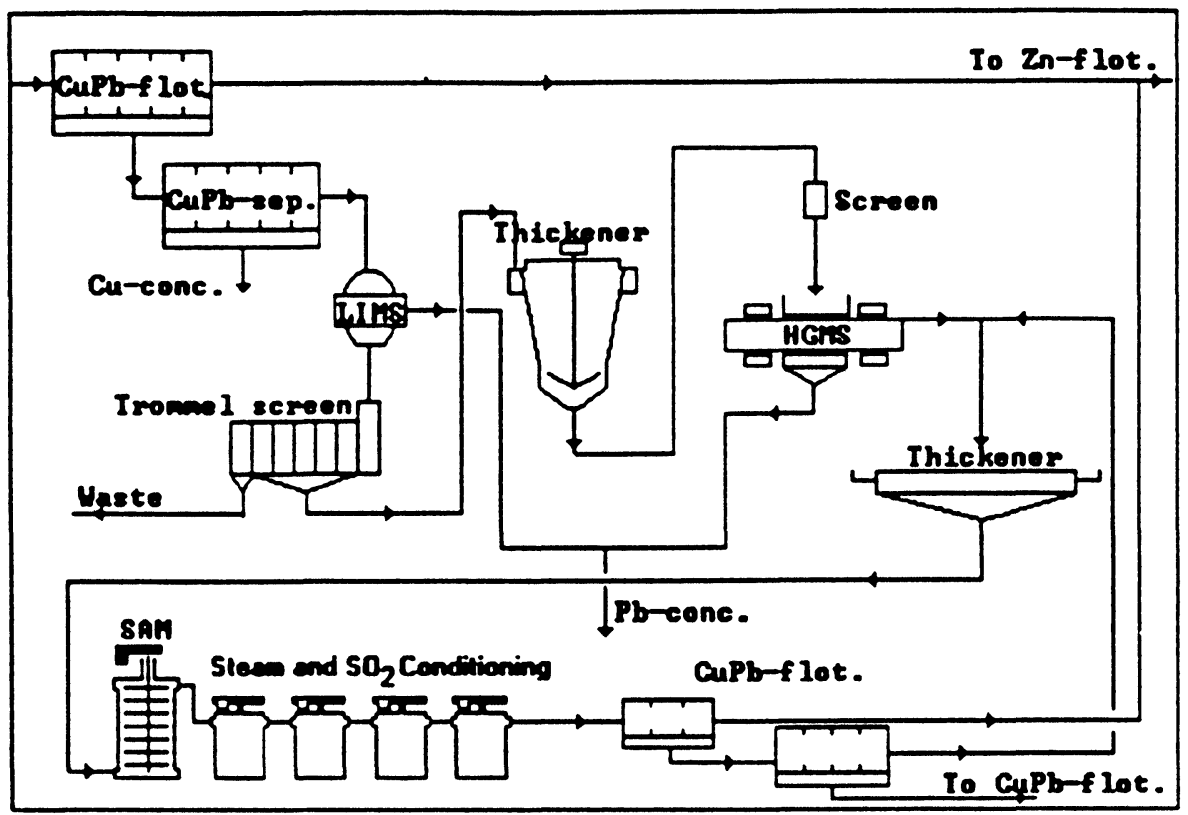

Fig. 1 A flowsheet for the HGMS circuit at the Boliden Garpenberg concentrator [1]. 
Before entering the HGMS, the slurry is treated with a low-intensity separator to remove magnetite and tramp iron while the oversize particles are removed by a screen. The non-magnetic product from HGMS is the final $\mathrm{Pb}$ concentrate. The magnetics containing mainly sphalerite, chalcopyrite, galena and iron-rich silicates from the gangue are further treated by flotation. Table 1 summarises metallurgical results from separation by HGMS.

Table 1 Metallurgical results in the HGMS circuit

\begin{tabular}{|l|l|l|l|l|l|l|l|l|}
\hline Product & $\begin{array}{l}\mathrm{Ag}, \\
\mathrm{ppm}\end{array}$ & $\begin{array}{l}\mathrm{Ag}, \\
\text { distr.\% }\end{array}$ & \multicolumn{1}{l}{$\begin{array}{l}\mathrm{Cu}, \\
\text { ass.\% }\end{array}$} & $\begin{array}{l}\mathrm{Cu}, \\
\text { distr.\% }\end{array}$ & $\begin{array}{l}\text { Zn, } \\
\text { ass.\% }\end{array}$ & $\begin{array}{l}\mathrm{Zn}, \\
\text { distr.\% }\end{array}$ & $\begin{array}{l}\text { Pb, } \\
\text { ass.\% }\end{array}$ & $\begin{array}{l}\mathrm{Pb}, \\
\text { distr.\% }\end{array}$ \\
\hline $\begin{array}{l}\text { Feed (Pb } \\
\text { conc.) }\end{array}$ & 1126 & 100.0 & 0.37 & 100.0 & 9.41 & 100.0 & 50.46 & 100.0 \\
\hline $\begin{array}{l}\text { HGMS } \\
\text { Pb conc. }\end{array}$ & 1414 & 90.9 & 0.45 & 85.3 & 5.70 & 43.8 & 60.84 & 87.3 \\
\hline $\begin{array}{l}\text { HGMS } \\
\text { Zn prod }\end{array}$ & 370 & 9.1 & 0.20 & 14.7 & 19.18 & 56.2 & 23.20 & 12.7 \\
\hline
\end{tabular}

It can be seen that HGMS reduces the $\mathrm{Zn}$ content in the lead concentrate from $10 \%$ to about $6 \%$, with little loss of silver [2]. Economical benefit of the HGMS installation in the flowsheet is significant. Removal of sphalerite and the fact that the iron-containing silicates such as tremolite and actinolite are also captured in HGMS reduces the amount of material in the galena concentrate. A $10 \%$ increase of lead in the concentrate was estimated. The purified concentrate has a higher value at the smelter. On the other hand, zinc formerly lost to the lead products is low, to a large extent, returned to the zinc concentrate in which it contributes to he revenue.

\section{Purification of Limestone by Wet Carousel HGMS}

The cyclic HGMS has been often selected for purification of industrial minerals such as kaolin clays. However, Figure 2 [3] shows installation of the carousel HGMS in the wet beneficiation plant of Svenska Mineral AB, Sweden. This 


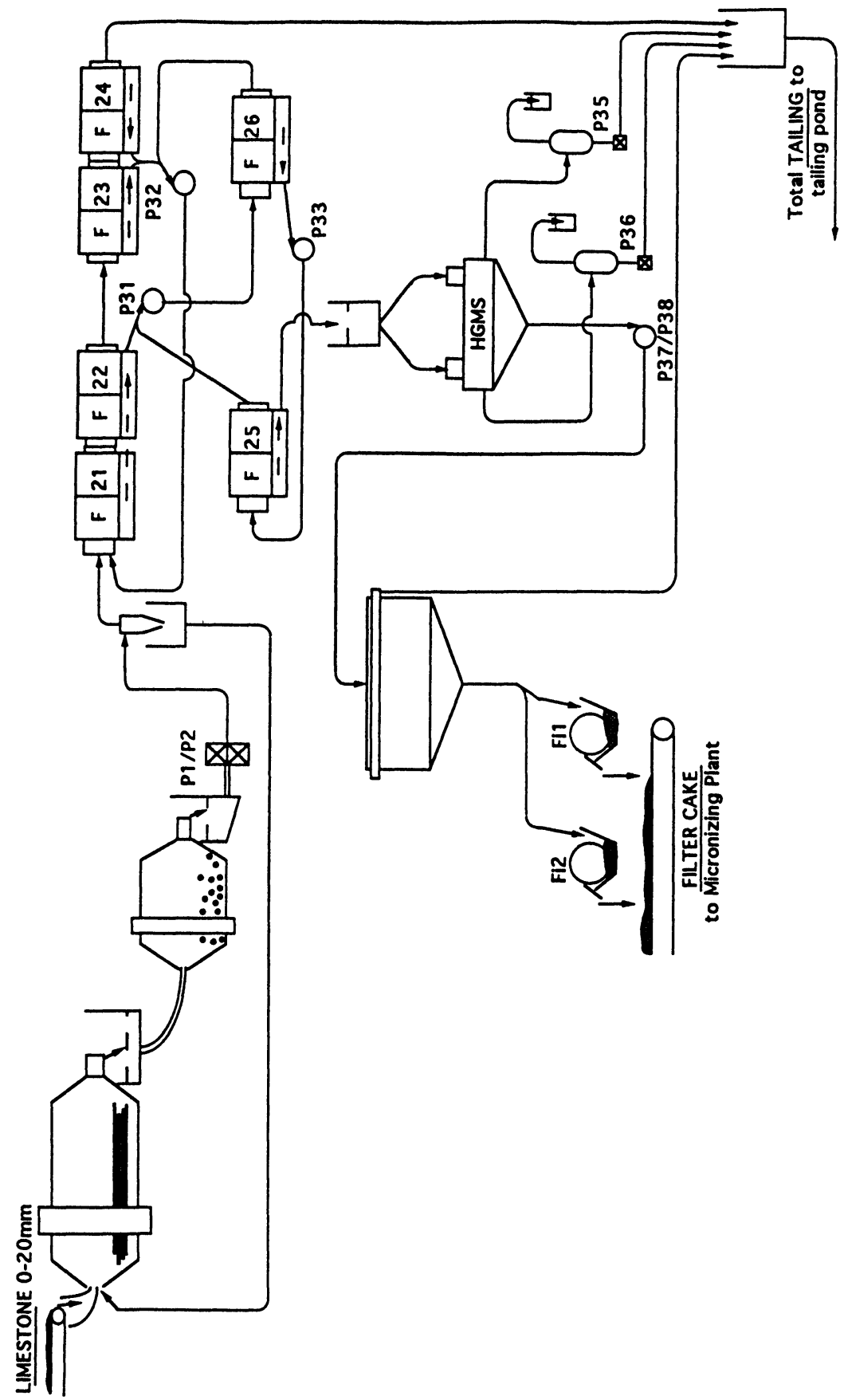

Fig. 2 Flowsheet of beneficiation of the Gåsgruvan limestone, Svenska Mineral AS, by flotation and high-gradient magnetic separation [3]. 
magnetic separator is Sala-HGMS 120-15-15 with two heads. Diameter of the separating ring is $120 \mathrm{~cm}$ and the maximum background magnetic field is 1.5 Tesla. The purpose of this HGMS installation was to remove iron-bearing impurities from the limestone product from flotation.

Wet HGMS, together with flotation of limestone, resulted in a high-grade concentrate at high recovery. The quality of the purified limestone after HGMS could meet demands for application as pigment and paper filler. Table 2 lists typical results of the production. Analysis of cost-efficiency has confirmed that the continuous solenoid HGMS can be applied to the purification of industrial minerals.

Table 2 Typical results of the production at Svenska Mineral AB [3]

\begin{tabular}{|l|l|l|l|ll|ll|}
\hline Product & $\begin{array}{l}\text { Yield, } \\
\text { wt\% }\end{array}$ & $\begin{array}{l}\mathrm{CaO}, \\
\text { ass.\% }\end{array}$ & $\begin{array}{l}\mathrm{CaO}, \\
\text { distr. } \\
\%\end{array}$ & $\begin{array}{l}\mathrm{MgO}, \\
\text { ass.\% }\end{array}$ & $\begin{array}{l}\mathrm{MgO}, \\
\text { distr.\% }\end{array}$ & $\begin{array}{l}\mathrm{Fe}_{2} \mathrm{O}_{3}, \\
\text { ass.\% }\end{array}$ & $\begin{array}{l}\mathrm{Fe}_{2} \mathrm{O}_{3}, \\
\text { distr.\% }\end{array}$ \\
\hline \hline Feed & 100.0 & 50.5 & 100.0 & 3.96 & 100.0 & 0.68 & 100.0 \\
\hline Flot prod. & 85.5 & 53.4 & 89.4 & 1.90 & 40.5 & 0.24 & 29.8 \\
\hline Flot. tail. & 15.5 & 34.7 & 10.6 & 15.2 & 59.5 & 3.08 & 70.2 \\
\hline HGMS prod. & 77.5 & 54.8 & 84.1 & 1.01 & 19.6 & 0.12 & 13.7 \\
\hline HGMS tail. & 7.0 & 38.2 & 5.3 & 11.5 & 20.9 & 1.54 & 16.1 \\
\hline Final tail. & 22.5 & 35.8 & 15.9 & 14.0 & 80.4 & 2.60 & 86.3 \\
\hline
\end{tabular}

\section{Removal of Impurities by Dry Rare-Earth Permanent Magnetic Roller}

In addition to the industrial applications of wet HGMS, rare-earth permanent magnetic roll separators have been used in the Swedish mineral processing industry. The first application of such a separator in the dry mode occurred in Nordkalk Kalcium $\mathrm{AB}$ to separate impurities containing $\mathrm{Fe}_{2} \mathrm{O}_{3}$ from calcite [4]. The machine used is the so-called "High-force" separator developed by International Process Systems, U.S.A. [5]. Basically, the High-force separator is a 
rare-earth magnetic roll with optimum ratios between thicknesses of the magnetic and steel disks.

The material to be separated was transported to the magnetic roll by a short thin and abrasion-resistant conveyor belt made either of steel or Kevlar. Thickness of the belt is very important for separation since the magnetic field intensity is greatly reduced at a distance from the magnet surface. The non-magnetic particles are discharged from the roll surface by gravitational and centrifugal forces, while the magnetic attraction force retains the magnetised particles.

The belt-tracking system in the High-force separator is very different compared with others [5]. The system offers a solution to the difficulty related to the small distance between the roll centres and to thin belts. It also allows the mounting of the rolls in removable cassettes. The results from the existing flowsheet have shown that the average $\mathrm{Fe}_{2} \mathrm{O}_{3}$ content in calcite could be reduced from $0.70 \%$ to $0.45 \%$, with reduction of $33 \%$ in a single pass. The size range of particles treated by magnetic separation was $-1.5+0.1 \mathrm{~mm}$.

\section{RESEARCH AND DEVELOPMENT}

\section{Dry Purification With the Advanced Magnetic Separators}

The separation performance of four magnetic separators applied to the improvement of the brightness of the final calcite product was investigated [6]. The four separators selected were Permroll (Bateman), induced magnetic roll (Humboldt Wedag), dry HGMS (Sala International AB) and High Force (Inprosys).

Of these four separators, only the dry HGMS is not a band-type separator. This dry HGMS is a newly designed HGMS system in the dry mode developed by Sala International $\mathrm{AB}$, Sweden. This separator consists of the control and power cabinet, solenoid and the airborne particle transportation and retrieval unit, as shown in Figure 3.

Particles transportation is accomplished by a compressed air-driven vacuum pump. The pump sucks the air through the heater into the separation circuit. The air inlet is placed at the feed point where the pre-heated air and the particles are 


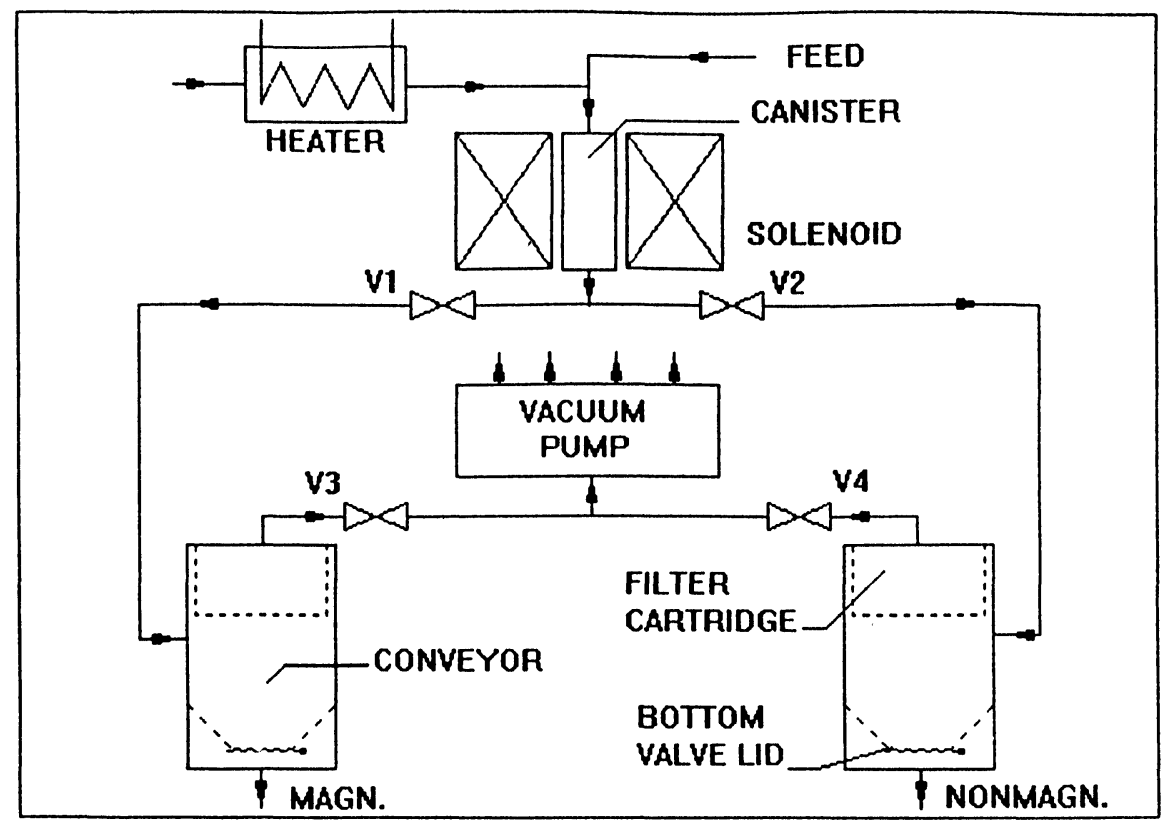

Fig. 3 A new dry HGMS system developed by Sala International AB [5]

mixed before entering the magnetised matrix. Material flows through the canister where magnetic particles are attached to the matrix filaments. The non-magnetic particles are carried by the air flow through the canister and pipes, into the filter unit of the conveyor. The material settles on the bottom valve lid.

The product bins are equipped with self-cleaning filter cartridges that effectively prevent dust and fine particles from entering the pump or the environment. When the magnet is turned off, the pneumatic valves are switched on and the air flow transports the magnetic product from the matrix to the second product bin.

Experiments have proved that the separation performance is much dependent on the air flow velocity and on the magnetic field strength. By increasing the magnetic field the quality of the product improves, while an increase in the air velocity is detrimental to the separation efficiency. The best performance was achieved at high magnetic fields and low air flow. The optimum air flow velocity is 
a compromise determined by the matrix type and the range of particle size of the feed material. This dry HGMS is especially useful for processing fine particles and materials with wide size distributions.

The results showed that the type of induced magnetic roll separator tested was not suitable for the purification of the calcite material. The Permroll and High Force separators produced material with excellent brightness but suffered from large losses of the material, particularly in fine fractions. This type of belt separators is most useful for separation of particles larger than $150 \mu \mathrm{m}$. The use of a steel belt and some additives to reduce the problem with electrostatic charging could possibly allow processing of particle sizes down to about $100 \mu \mathrm{m}$.

If wide mixtures of particles with wide size distribution are to be processed it must be made clear that the belt-type separators will also affect the particle size distribution. The mean particle size in the non-magnetic product will be considerably greater than in the feed. This is due to the fact that the separator acts as a classifier, losing fines to the magnetics.

One advantage of the belt-type separators is their insensitivity to oversize particles. These may not separate properly but they will not interfere or obstruct the separator.

It was proven that the dry HGMS was particularly useful for fine particle processing. The use of the matrix allows particles of different sizes to be processed simultaneously. Dry HGMS gave the best results in the purification of particles in the size range $-150 \mu \mathrm{m}+38 \mu \mathrm{m}$. The brightness of the non-magnetic product was comparable to the results from belt separators. The recovery of the product was much higher with dry HGMS. Dry HGMS thus extends the possibility of dry separation to fine particles, beyond limits of belt separators.

\section{Selectivity of Wet Magnetic Separation}

It is known that the selectivity of wet magnetic separation can be improved by adjusting the $\mathrm{pH}$ value of the slurry and by changing the aggregation/dispersion state of particles. A study was made to investigate, theoretically and experimentally, the selectivity of wet HGMS with a mixture of hematite and 
quartz ultrafines $(<10 \mu \mathrm{m})$ by adjusting the $\mathrm{pH}$ value of the slurry and to determine conditions under which the separation efficiency is maximised [7].

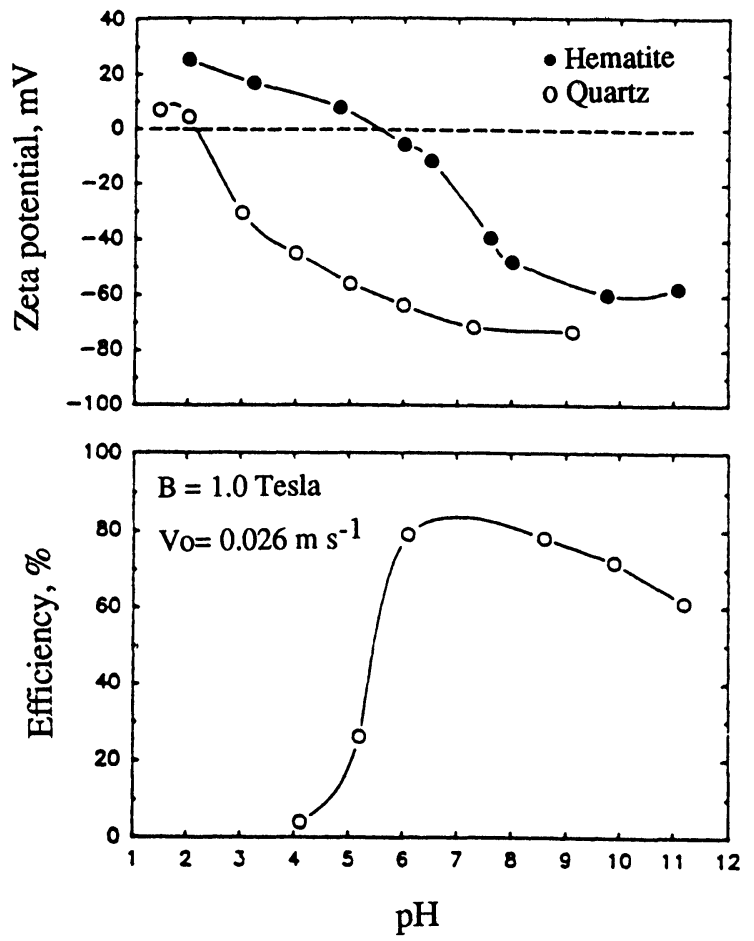

Fig. 4 Improvement of selectivity of wet HGMS by adjusting the $\mathrm{pH}$ value of the hematite-quartz slurry

The results shown in Figure 4 indicate that the hematite ultrafines and its aggregates could be selectively attracted on the matrix in wet HGMS, since the net attraction energy favoured their contact at $\mathrm{pH}=6.5$, about one $\mathrm{pH}$ unit above point-of-zero charge $\mathrm{pH}_{\mathrm{pzc}}$ of hematite. The inclusion of quartz particles in the magnetic fraction was due mainly to heterocoagulation with hematite particles and could occur at a slightly lower $\mathrm{pH}$ value. A phenomenon of this type resulted in the non-selective separation of those dissimilar particles by wet HGMS.

The adherence of quartz particles to hematite particles or even to the matrix might be eliminated by performing the separation under slightly higher $\mathrm{pH}$ 
conditions so that the dissimilar mineral particles had the same negative potentials, but about one $\mathrm{pH}$ unit above $\mathrm{pH}_{\mathrm{pzc}}$ of hematite. The latter requirement should favour homocoagulation between hematite ultrafines but prevent heterocoagulation of hematite and quartz.
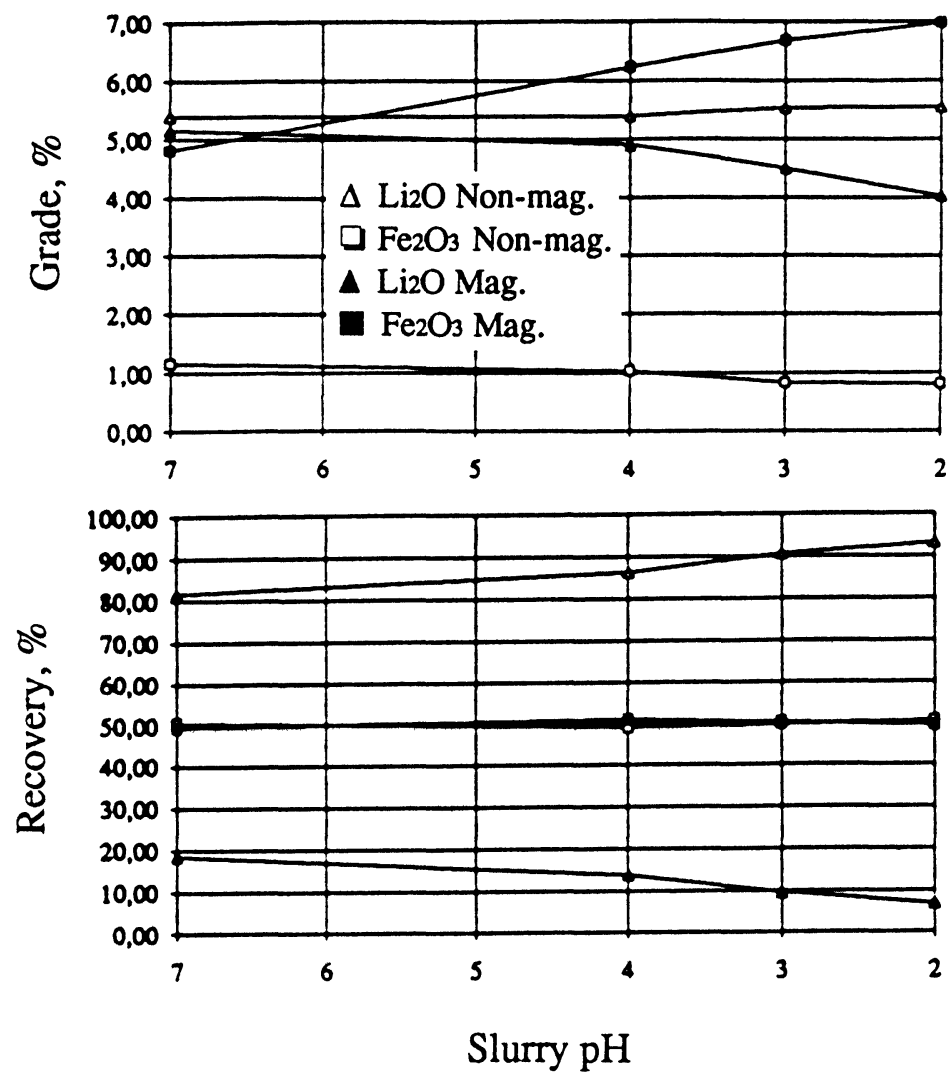

Fig. $5 \quad \mathrm{Li}_{2} \mathrm{O}$ and $\mathrm{Fe}_{2} \mathrm{O}_{3}$ grades and recoveries in the magnetic and non-magnetic fractions, at various values of $\mathrm{pH}$

The analysis of total interaction energies in the particle-particle and particle-matrix system in wet HGMS provided a good explanation of the experimental results. Furthermore, the $\mathrm{pH}$ influence on magnetic separation of chromite ore was also examined [8]. The increase in the $\mathrm{Cr}_{2} \mathrm{O}_{3}$ recovery due to the improvement of the selectivity makes the process more efficient and economic. 
In another example, minerals coated with surface-active compounds after flotation are to be separated in wet HGMS [9]. Although the physics of magnetic separation deals with volume-dependent parameters rather than surface properties, the collector might well have a significant effect on the separation results. It was assumed that the surfaces of the majority of various minerals reporting to the float product were covered with the collector and hence had a strong tendency to form flocs. These particle group would behave as individual bodies with a bulk susceptibility that is dependent on the minerals enclosed. If the collector is responsible for forming the flocs, regeneration of the particle surface or deactivation of the collector would improve the particle dispersion and the selectivity of separation.

A series of tests carried out on a fatty acid floated spodumene concentrate proved the importance of the dispersion by adjusting the slurry $\mathrm{pH}$ value. The tall oil-type fatty acid on the spodumene surface was deactivated by reducing the $\mathrm{pH}$. Tests were made with adjusting the $\mathrm{pH}$ value from 7 to 2 . The results shown in Figure 5 indicate that the recovery of lithia to the non-magnetic product was greatly improved as the $\mathrm{pH}$ dropped. Decreasing the $\mathrm{pH}$ of the slurry resulted in an increase of the $\mathrm{Li}_{2} \mathrm{O}$ recovery by more than $11 \%$. The non-magnetic product was to be the final spodumene concentrate and the iron-rich magnetic fraction constituted tailings.

\section{Wet Recovery of Weakly Magnetic Mineral Fines and Ultrafines}

Efficient recovery of fine and ultrafine particles is crucial to the processing of fine-grained ore bodies or the re-processing of tailings. Magnetic separation has its own potential due to the advent of HGMS and WHIMS techniques. These techniques have been applied for recovering weakly magnetic minerals from slimes. However, problems concerning very fine particles have not been fully solved. Our studies [10] showed that wet HGMS with industrial matrices was efficient for concentration of weakly magnetic minerals (hematite and chromite), as small as 10 $\mu \mathrm{m}$. Below this size, however, the separation efficiency was found to be poor.

Therefore, modifications of the existing magnetic technology, or alternative methods were investigated for efficient recovery of particles below $10 \mu \mathrm{m}$ which 
escaped from the existing separators. These methods or techniques included "carrier" or "piggy-back" method, aggregation with magnetic bonding and hydrophobic magnetite seeding.

Carrier phenomenon. It was observed that "carrier" coagulation occurred when treating a chromite ore slime (Kemi, Finland) by wet HGMS [11]. In these experiments, a mixture was prepared of the $<10 \mu \mathrm{m}$ fraction with $<53>38 \mu \mathrm{m}$ fraction. The results in Table 3 show that the presence of coarse particles of $<53>38 \mu \mathrm{m}$ improved the overall recovery of $\mathrm{Cr}_{2} \mathrm{O}_{3}$ and the grade of the magnetic product in the slimes. Also, the recovery and the grade became dependent on the $\mathrm{pH}$ value of the slurry. Good results were obtained at high $\mathrm{pH}$ values (9.5 to 9.9).

Table 3 HGMS results with the chromite slimes smaller than $10 \mu \mathrm{m}$, in the presence or absence of the "carrier"

\begin{tabular}{|c|c|c|c|c|c|c|c|}
\hline \multirow[b]{2}{*}{$\mathrm{pH}$} & \multirow[b]{2}{*}{ Product } & \multicolumn{3}{|c|}{$\begin{array}{l}\text { No } \\
\text { carrier }\end{array}$} & \multicolumn{3}{|c|}{$\begin{array}{l}\text { With } \\
\text { carrier }\end{array}$} \\
\hline & & $\begin{array}{l}\text { Grade } \\
\% \mathrm{Cr}_{2} \mathrm{O}_{3} \\
\end{array}$ & $\begin{array}{l}\text { Recov. } \\
\% \mathrm{Cr}_{2} \mathrm{O}_{3}\end{array}$ & $\mathrm{Cr}: \mathrm{Fe}$ & $\begin{array}{l}\text { Grade } \\
\% \mathrm{Cr}_{2} \mathrm{O}_{3} \\
\end{array}$ & $\begin{array}{l}\text { Recov. } \\
\% \mathrm{Cr}_{2} \mathrm{O}_{3}\end{array}$ & $\mathrm{Cr}: \mathrm{Fe}$ \\
\hline \multirow[t]{2}{*}{$4.5-4.9$} & Mag & 35,00 & 53,58 & 1,62 & 36,90 & 58,74 & 1,41 \\
\hline & Non-mag & 9.50 & 46.42 & 1.33 & 9.06 & 41.26 & 1.32 \\
\hline \multirow[t]{2}{*}{$7.6-8.0$} & Mag & 35,09 & 60,37 & 1,56 & 37,43 & 62,57 & 1,43 \\
\hline & Non-mag & 8,19 & 39,63 & 1,17 & 8,33 & 37,43 & 1,33 \\
\hline \multirow[t]{2}{*}{$9.5-9.9$} & Mag & 34,00 & 61,27 & 1,57 & 37,47 & 66,67 & 1,47 \\
\hline & Non-mag & 8,00 & 38,73 & 1,24 & 7,60 & 33,33 & 1,33 \\
\hline \multirow[t]{2}{*}{11.3} & Mag & 33,00 & 59,13 & 1,56 & 38,45 & 63,43 & 1,42 \\
\hline & Non-mag & 8,30 & 40,87 & 1,32 & 8,19 & 36,57 & 1,33 \\
\hline
\end{tabular}

It is well known that in the treatment of a natural ore the surface charge of the valuable mineral may be also affected by other cationic species which may be released into the slurry from the lattice of gangue minerals. It was proved [12] that $\mathrm{Ca}^{2+}$ and $\mathrm{Mg}^{2+}$ ions were detected in the Kemi chromite slurry which appeared to be released from the major minerals such as dolomite and magnesite. Electrodynamic measurements showed that the $\mathrm{pH}_{\mathrm{pzc}}$ of the chromite in the ore 
slurry might be increased to the $\mathrm{pH}$ range 8 to 11 . The results could explain why the overall recovery and the grade of the magnetic fraction in the slimes was improved in the presence of the "carrier" of $<53>38 \mu \mathrm{m}$ at higher $\mathrm{pH}$.

It was suggested that in the presence of a sufficiently strong magnetic field ( $>1.0$ Tesla), the secondary minimum can be sufficiently deep to prevent the particle aggregates from disintegration. In the absence of the magnetic field, particles slowly coagulate in the primary minimum only, for cases of no electrostatic repulsion. If a high magnetic field is applied in the course of the carrier coagulation, the clusters can appear. Such a mechanism is possible only if the carrier coagulation takes place in the secondary minimum, as is indicated by the nature of the interparticle energy functions [11]. The "carrier" coagulation may play a role in the capture of valuable slimes in high magnetic fields.

Aggregation due to magnetic bonding. Magnetic effects on aggregation of weakly magnetic natural mineral particle ultrafines was investigated. It was indicated that particle aggregation occurred either with induced magnetic moment excited by an external magnetic field [13], or with magnetic moment due to the remanent magnetisation [14].

The magnetic-field induced aggregation of the mineral ultrafines $\left(d_{50} \approx 3\right.$ to $4 \mu \mathrm{m}$ ), such as hematite or chromite, in aqueous suspensions at moderate ionic strength, was studied using a system of magneto-sedimentation analysis [13]. The main feature of the experiments was that at magnetic induction values above 1.0 Tesla, particle aggregation occurred forming chains and rings. Particles within the chains showed considerable mobility, possibly due to thermal motion. The chain formation was explained by "secondary minimum aggregation", at large interparticle distances.

However, the interparticle bond strength was sufficiently high to prevent the chains from disintegrating during sedimentation. Figure 6 shows how a rapid increase in the field-induced aggregation can be seen to occur at a fairly well-defined value of the external magnetic field. This value may be taken as an approximate threshold value of the magnetic field for these mineral systems, and in the tests it is most pronounced for these plots and corresponds to magnetic induction of 0.5 to 0.6 Tesla. 


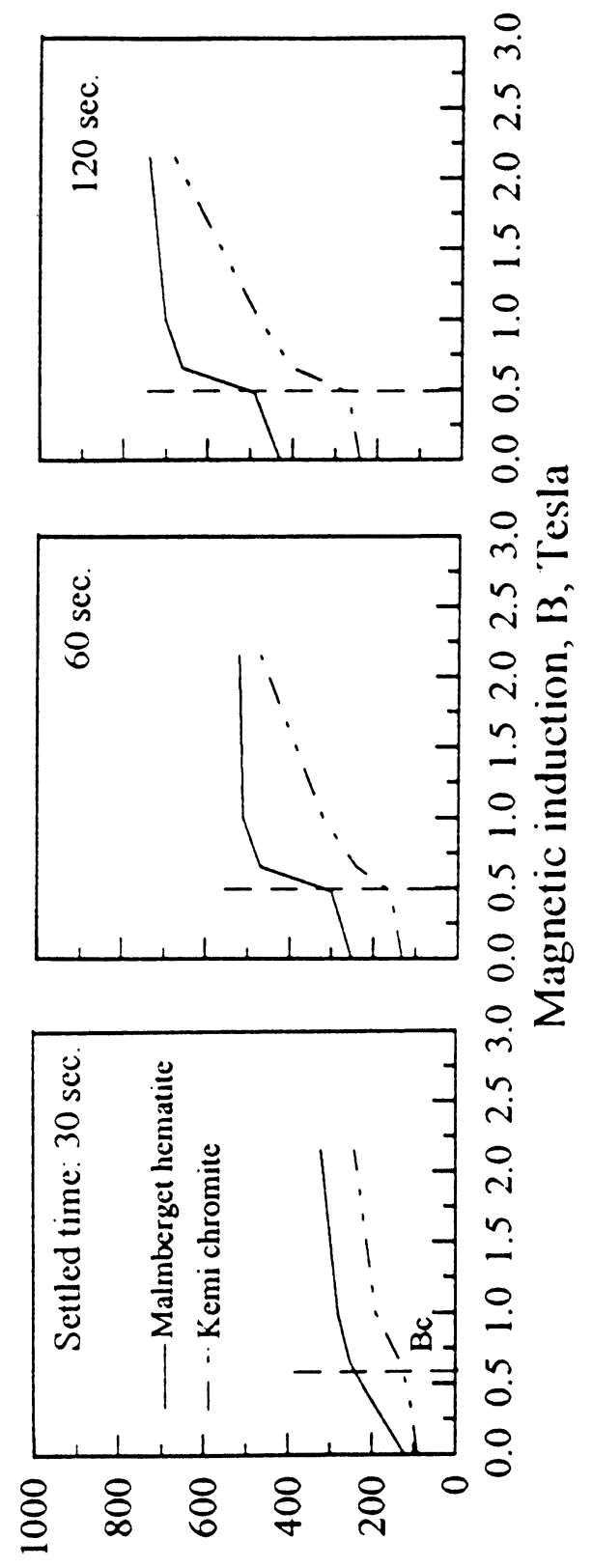

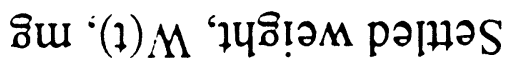

Fig. 6 Particle aggregation due to magnetic fields 
It is interesting to see in Figure 7 that the hematite ultrafines of two ore slimes, in a well dispersed slurry were selectively aggregated with $<10 \mu \mathrm{m}$ magnetite, in the absence of the aggregation reagents, high shear rates or an external magnetic field [14]. The results of the aggregation/settling experiments showed the improvements in both the Fe content and Fe recovery in the aggregation portion, in the presence of magnetite particles at $\mathrm{pH}=11$.

The formation of the aggregates was attributed to the presence of the remanent magnetisation in these oxide iron minerals, mainly in magnetite. This method may find possible application in the pre-concentration or concentration of hematite ultrafines, or in the removal of hematite impurities from other valuable minerals. The magnetic bonding between magnetite and hematite could be one of the contributing factors to the heteroaggregation process in addition to electrolytic coagulation, hydrophobic bonding and polymer bridging.

Hydrophobic magnetite seeding in wet HGMS. The application of hydrophobic magnetite seeding to concentrate the hematite fines $<10 \mu \mathrm{m}$ in the slimes using an industrial matrix HGMS was investigated [15]. In this study, oleate was used to induce hydrophobic heteroaggregation between hematite fines and and magnetite seeds. Intensive stirring was responsible for effective particle contact.

It was indicated that fairly low magnetic fields were sufficient to capture the weakly magnetic ultrafines seeded with colloidal magnetite, at adaptable slurry velocities in the HGMS. Important factors to be taken into consideration in this technique are: surface chemistry of the magnetite seeds and of the desired particles, the $\mathrm{pH}$ effect on the system, the concentration of oleate, hydrodynamic conditions of the slurry, the mode of introducing the seeds as well as the system of magnetic separation. since this technique can separate non-magnetic or weakly magnetic ultrafine components, it may find its application in the recovery of rare and precious metals and minerals.

\section{ACKNOWLEDGMENT}

The financial contribution from the Swedish Mineral Processing Research Foundation (MinFo), and the Swedish National Board for Technical Development is gratefully acknowledged. 

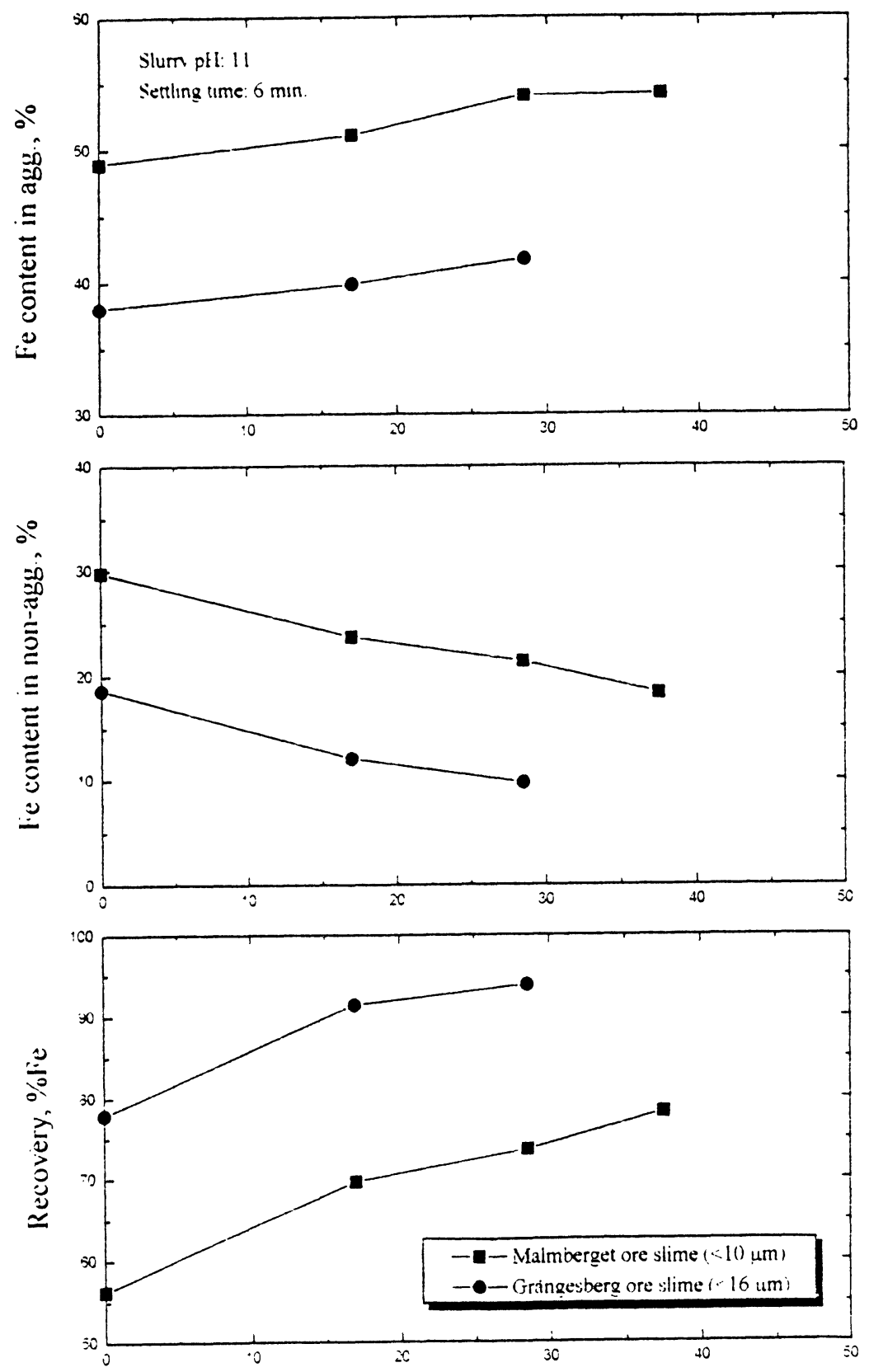

Add. of $<10$ um magntite, $\%$

Fig. 7 The aggregation phenomenon between magnetite and hematite ultrafines 


\section{REFERENCES}

[1] B. Johansson: Separation of complex sulphide minerals concentrate by high-intensity and high-gradient magnetic separation. Proc. Conf. Mineral Processing, Luleå, Sweden (1990), 105 (in Swedish)

[2] J. Jirestig and E. Forssberg: Magnetic separation of sulphide minerals. MIner. Metall. Proc. No. 11 (1993), 176

[3] M. Gräsberg: Beneficiation of limestone. Proc. Conf. Mineral Processing, Luleå, Sweden (1992), 63 (in Swedish)

[4] L. Sunnebo: Purification of calcite. Preprints of Conf. Mineral Processing, Luleå, Sweden (1995), 181 (in Swedish)

[5] International Process Systems Inc., INPROSYS News \& Information Letter 1, March 1992

[6] J. Jirestig and B. Zsolt: Dry magnetic methods for separation of minerals. Technical Report MinFo No. 61203, Stockholm, Sweden (1992)

[7] Y. Wang, E. Forssberg and R. Pugh: The influence of $\mathrm{pH}$ on wet high-gradient magnetic separation of $<10 \mu \mathrm{m}$ particles of hematite and quartz. Intl. J. Min. Proc. 36 (1992), 93

[8] Y. Wang and E. Forssberg: Possible effect of coarse weakly magnetic mineral particle on recovering the ultrafines in HGMS. Technical Report MinFo No. 60908 (1991)

[9] J. Jirestig and E. Forssberg: Dispersion of flotation concentrates before magnetic separation. Min. Engn. 7 (1994), 1505

[10] Y. Wang and E. Forssberg: Particle size dependence on the performance of HGMS for treatment of mineral slimes. Scand. J. Metall. 21 (1992), 121

[11] Y. Wang, R. Pugh and E. Forssberg: Carrier coagulation of chromite fines in wet magnetic separation. Magn. Electr. Sep. 5 (1993), 33

[12] Y. Wang and E. Forssberg: The recovery of hematite and chromite fines and ultrafines by wet magnetic methods. Miner. Metall. Proc., May 1994, 87

[13] Y. Wang, R. Pugh and E. Forssberg: The influence of interparticle surface forces on the coagulation of weakly magnetic mineral ultrafines in a magnetic field. Colloids and Surfaces A: Physicochemical and Engineering Aspects 90 (1994), 117

[14] Y. Wang and E. Forssberg: Aggregation between magnetite and hematite ultrafines utilising remanent magnetisation. Min. Engn. 5 (1992), 895

[15] Y. Wang, E. Forssberg and R. Pugh: Hydrophobic magnetite seeding of hematite ultrafines in high gradient magnetic separation. Min. Engn. 6 (1993), 537 
Yanmin Wang: For biography see Magn. Electr. Sep. 5 (1993), 52

E. Forssberg: For biography see Magn. Electr. Sep. 4 (1992), 31

Keywords: Magnetic separation, HGMS, magnetic seeding, magnetic aggregation, ultrafines, Sweden 